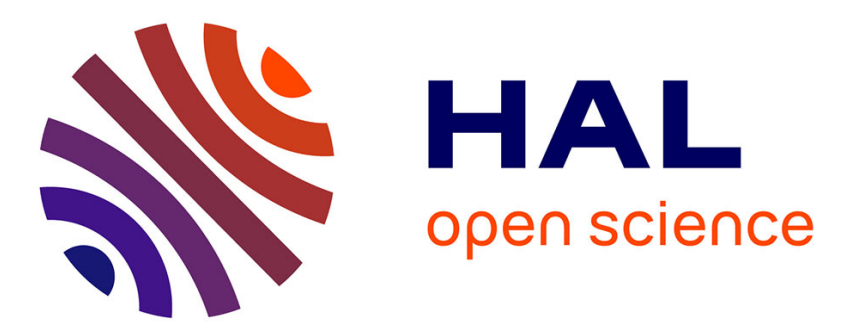

\title{
Selection of single-chain antibodies that specifically interact with vesicular stomatitis virus (VSV) nucleocapsid and inhibit viral RNA synthesis.
}

Jean-Claude Cortay, Denis Gerlier, Frédéric Iseni

\section{- To cite this version:}

Jean-Claude Cortay, Denis Gerlier, Frédéric Iseni. Selection of single-chain antibodies that specifically interact with vesicular stomatitis virus (VSV) nucleocapsid and inhibit viral RNA synthesis.. Journal of Virological Methods, 2006, 131 (1), pp.16-20. 10.1016/j.jviromet.2005.06.021 . hal-00175649

\section{HAL Id: hal-00175649 \\ https://hal.science/hal-00175649}

Submitted on 29 Sep 2007

HAL is a multi-disciplinary open access archive for the deposit and dissemination of scientific research documents, whether they are published or not. The documents may come from teaching and research institutions in France or abroad, or from public or private research centers.
L'archive ouverte pluridisciplinaire HAL, est destinée au dépôt et à la diffusion de documents scientifiques de niveau recherche, publiés ou non, émanant des établissements d'enseignement et de recherche français ou étrangers, des laboratoires publics ou privés. 
Selection of single-chain antibodies that specifically interact with vesicular stomatitis virus (VSV) nucleocapsid and inhibit viral RNA synthesis.

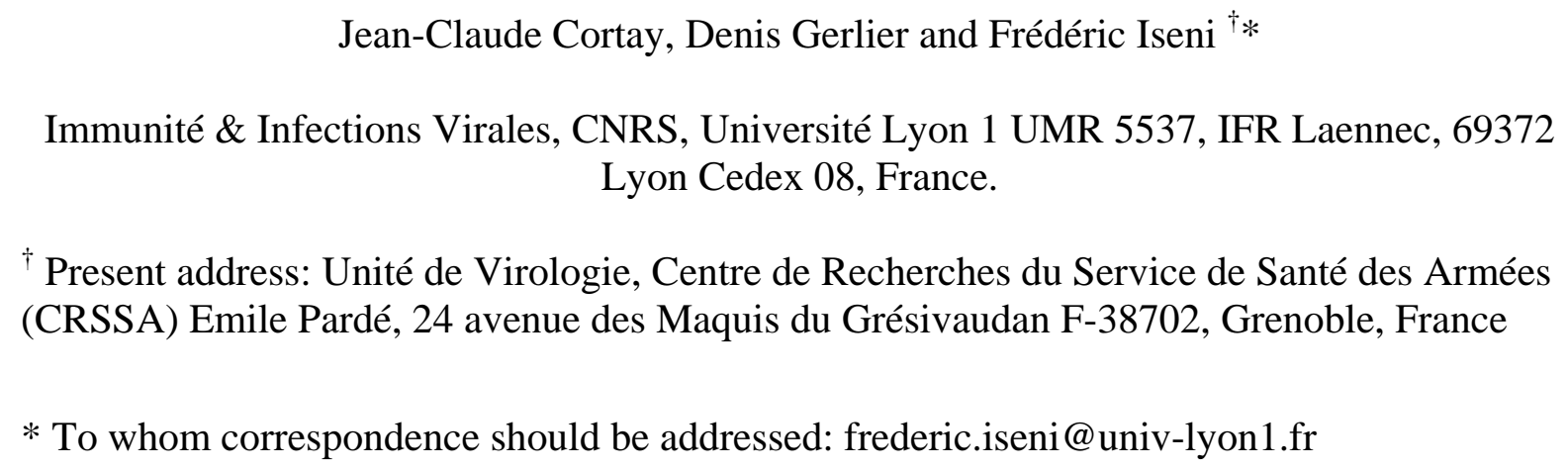

* To whom correspondence should be addressed: frederic.iseni@univ-lyon1.fr

Running title: single-chain antibodies against VSV nucleocapsid inhibit viral RNA synthesis Keywords: scFv, phage display, nucleocapsid, VSV

Number of words: Text: 2481, Summary: 142 2 3 Summary The RNA genome of nonsegmented negative-strand RNA virus is completely covered by the nucleoprotein $(\mathrm{N})$ forming a ribonucleoprotein complex, the nucleocapsid. The nucleocapsid functions as the template for viral RNA synthesis that is mediated by a viral RNA-dependent RNA polymerase. We postulated that the selection of molecules that would specifically target the nucleocapsid and thus inhibit the viral polymerase activity could represent a common approach to block negative-strand RNA viruses. We present the characterization of two single-chain antibody fragments (scFv) that were selected using the phage display technology and that specifically interacted with vesicular stomatitis virus (VSV) nucleocapsid. The two recombinant antibodies recognize a conformational epitope on the nucleocapsid and specifically immunoprecipitate nucleocapsids from infected cell extracts. Both antibodies have a strong inhibitory effect on VSV transcription activity in vitro and thus represent promising molecules to inhibit viral RNA synthesis in vivo. 
Vesicular stomatitis virus (VSV), a pathogen for domestic cattle, is a member of the Rhabdoviridae family. The genetic organization of Rhabdoviridae is similar to Paramyxoviridae and Filoviridae that belong to the same order of Mononegavirales (Rose, 2001). Viruses belonging to this order such as Newcastle diseases and rinderpest have a major economic impact on animal rearing, and many others are responsible of numerous diseases in humans that range from acute respiratory diseases (respiratory syncytial and parainfluenza viruses) to hemorrhagic fever (Ebola and Marburg viruses) and encephalitis (Hendra and Nipah viruses).

In many aspects, transcription and replication of these single strand, negative-sense RNA viruses are similar (Whelan et al., 2004). In infected cells, RNA synthesis is restricted to the cytoplasm and is mediated by the viral RNA-dependent RNA polymerase that is only active on the genomic/antigenomic RNA tightly enwrapped by the nucleoprotein $(\mathrm{N})$. This ribonucleoprotein complex, or nucleocapsid, serves as a template for both mRNA synthesis and replication.

Although different vaccines have been developed against few Mononegavirales a general antiviral strategy to block these viruses is still lacking. Molecules that would specifically target the nucleocapsids and inhibit viral RNA synthesis would lead to the development of new antiviral drugs.

Recently, a new class of neutralizing molecules called intracellular antibodies (intrabodies) has been described (Chen et al., 1994, Marasco, 1997). Single-chain antibody fragments (scFv) have been successfully used to inhibit the function of certain intracellular target proteins and were shown to have promising therapeutic applications (Lobato \& Rabbitts, 2003, Rondon \& Marasco, 1997, Stocks, 2004). ScFv consists of a single polypeptide chain that contains the variable regions of heavy $\left(\mathrm{V}_{\mathrm{H}}\right)$ and light $\left(\mathrm{V}_{\mathrm{L}}\right)$ chain separated by a short polypeptide linker (Clackson et al., 1991, McCafferty et al., 1990). These recombinant antibodies are produced from combinatorial libraries of immunoglobulin genes that are functionally expressed on the surface of filamentous phages (Griffiths et al., 1994). High affinity antibodies that are specific of a target protein are selected during several rounds of in vitro affinity selection. ScFv directed against the target protein can then be expressed inside cells and their inhibitory properties can be evaluated (Maciejewski et al., 1995, Marasco et al., 1993, Mhashilkar et al., 1995).

As a proof of concept, we report the identification of two recombinant antibodies (scFv) that have been selected to specifically recognize VSV nucleocapsids. These antibodies 
have a strong inhibitory effect on VSV transcription in vitro and may represent promising molecules to block viral RNA synthesis in vivo.

To select for human anti-nucleocapsid antibodies by phage display, nucleocapsids of VSV Indiana strain were purified from BHK-21 (baby hamster kidney) infected cells. Twenty hours post-infection cells were collected and lysed into a $0.6 \%$ NP-40 containing buffer. The lysate was loaded onto a 20-40\% CsCl gradient (W/W) and centrifuged for 17 hours at 32000 r.p.m. in a SW 41 rotor. The pure nucleocapsids that form a visible band in the gradient were recovered by puncture of the tube and dialysed against PBS. Previous reports have shown that the nucleocapsids purified in these conditions are transcriptionally active in in vitro assay (Moyer et al., 1991). One microgram of purified nucleocapsid, analysed by SDS-PAGE reveals a single band with the expected $45 \mathrm{kDa}$ molecular mass of the nucleoprotein (Fig 1A, lane 1). The nucleocapsids were then biotinylated, in vitro, by the addition of NHS-LC-Biotin (PIERCE) in a 1:1 molar ratio. The reaction was performed at room temperature, for 1 hour, on a rotating wheel and stopped by adjusting the reaction to $100 \mathrm{mM}$ glycine. Non-reacted biotin was removed by ultrafiltration through a $100 \mathrm{kDa}$ MWCO Vivaspin concentrator device (Vivascience). No significant change in the migration of the nucleoprotein on SDSPAGE was observed upon biotinylation (Fig 1A, compare lanes 1 and 2).

For the panning step, $100 \mu \mathrm{g}$ of biotinylated nucleocapsids were incubated with $50 \mu \mathrm{l}$ of streptavidin-coupled magnetic beads (Streptavidin M-280 Dynabeads, Dynal) in binding buffer (PBS $+0,1 \%$ Tween 20) for two hours, end over end, at $4^{\circ} \mathrm{C}$. The beads were then recovered on a magnet. To estimate the yield of captured nucleocapsids, the streptavidincoated beads were analysed on SDS-PAGE. In these conditions, 5 to $10 \mu \mathrm{g}$ of nucleocapsids were reproducibly bound to the magnetic beads (Fig 1A, lanes 3 and 4).

The human Tomlinson I+J library (obtained from the MRC Centre for Protein Engineering, Cambridge, UK) was used for affinity selection of anti-nucleocapsid antibodies. This library contains more than 200 million different scFvs, each one consisting of a single polypeptide composed of the VH and VL immunoglobulin variable regions separated by a flexible glycine/serine-rich linker. The rounds of selection were essentially performed according to the manufacturer's instructions (http://www.hgmp.mrc.ac.uk/geneservice/reagents/products/datasheets/scFv/tomlinsonIJ.pdf). Briefly, biotinylated nucleocapsids bound to streptavidin-coated beads were incubated with 1.5.10 ${ }^{12} \mathrm{scFv}$ displaying phages in binding buffer complemented with $2 \%$ fat-free milk (Marvel) for 1.5 hour at $4^{\circ} \mathrm{C}$. After twenty washes in binding buffer, the nucleocapsid-bound 
phages were eluted with $100 \mathrm{mM}$ triethylamine (pH11) and amplified in the Escherichia coli TG1 strain to achieve the next round of selection. As shown in figure $1 \mathrm{~B}$, the phage recovery yield increased about $10^{3}$ folds over the three rounds, indicating a positive selection. Thus, we stopped the selection after the third round and randomly picked 25 clones of the phagemidcontaining TG1 cells. The supernatant of each clone (secreting a single scFv) was tested by ELISA for its ability to bind to purified nucleocapsids (data not shown). Seven scFvs reacted positively in that assay. DNA sequencing of each positive clones revealed that six of them were identical showing the effectiveness of the selection. The protein sequence of two different positive clones (named Nuc 3 and Nuc 25) is shown in figure 1C. The sequence of Nuc 1, which was initially selected but was not reactive in ELISA, is also presented.

For functional characterization, the soluble (His) ${ }_{6}$-tagged scFvs were produced in the E. coli HB 2151 strain and purified from the periplasmic space by immobilized metal affinity chromatography (IMAC) using a Ni-Sepharose High Performance resin (Pharmacia Biotech) as described by the manufacturer. The eluted scFvs migrated as a single band on Coomassie blue stained SDS-PAGE (data not shown). A one-liter bacterial culture yielded from 2 to 10 mg of scFv that were kept at $-20^{\circ} \mathrm{C}$ in $50 \%$ glycerol.

The purified Nuc 3 and Nuc 25 antibodies failed to recognize VSV nucleoprotein in Western blotting experiments (data not shown). However, the two scFvs were reactive in dot blot assay when cytoplasmic extracts from VSV-infected cells were blotted onto a nitrocellulose membrane (Fig 2A). Both antibodies are highly specific of a viral antigen since no background reactivity could be detected in non-infected cytoplasmic extract. Furthermore, Nuc 1 did not react with VSV infected cell extract. The observation that these antibodies were reactive against native antigens (in dot blot assay) and failed to bind to denatured ones (in Western blot assay) indicated that they did recognize a conformational epitope. This observation led us to ask whether these antibodies could be efficiently used in immunoprecipitation experiments.

To determine the ability of Nuc 3 and Nuc 25 to immunoprecipitate nucleocapsids

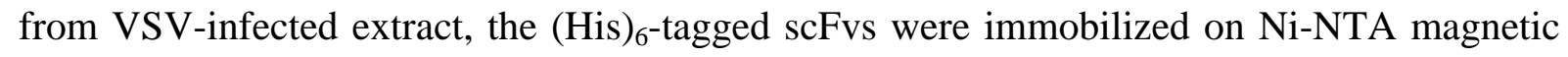
agarose beads (Qiagen) and incubated with protein extracts. After three washes in stringent saline conditions (PBS buffer supplemented with $0.5 \mathrm{M} \mathrm{NaCl}$ ), proteins bound to the antibodies were separated by SDS-PAGE and immunoblotted with an anti-VSV polyclonal antibody. In theses conditions Nuc 3 and Nuc 25, but not Nuc 1, could efficiently immunoprecipitate the nucleocapsids produced in VSV-infected cells (Fig 2B). The specificity of the interaction between the antibodies and the nucleocapsid was analysed by 
138 Coomassie blue staining of the same immunoprecipitated samples. The gel in figure 2C shows that even though the 2 scFvs were mixed with a large amounts of infected extracts $(1,7 \mathrm{mg})$, only the nucleocapsids were immunoprecipitated and no contaminant protein could be detected. This data confirms the high specificity of the selected antibodies towards VSV nucleocapsids.

The recombinant antibodies were then used for immunostaining of VSV-infected cells. Vero cells were fixed 8 hours post-infection in $4 \%$ paraformaldehyde, and permeabilised with $0.3 \%$ Triton X-100. As shown in Fig 2D, both Nuc 3 and Nuc 25 labelled prominent cytoplasmic inclusion bodies that are characteristic of nucleocapsids (Arnheiter et al., 1985). These structures were neither observed in the non-infected cells shown in the same field nor in cells labelled with the control antibody Nuc 1.

All together, our data clearly demonstrated that the two recombinant antibodies selected by the phage display approach recognized VSV nucleocapsids with high specificity. This observation prompted us to evaluate the potential inhibitory properties of Nuc 3 and Nuc 25 on VSV RNA synthesis. For this purpose in vitro transcription of detergent-disrupted VSV was performed in the presence of Nuc 3 and Nuc 25. In this assay, $5 \mu$ g of glycerol gradientpurified VSV (disrupted into a mix containing $0.2 \%$ Triton X-100, $100 \mathrm{mM}$ Tris-HCl (pH 8), $70 \mathrm{mM} \mathrm{NaCl}, 5 \mathrm{mM} \mathrm{MgCl}$, $1 \mathrm{mM} \mathrm{DTT}, 5 \mathrm{mM}$ spermidine) were incubated for $15 \mathrm{~min}$ at 4 ${ }^{\circ} \mathrm{C}$ with the different scFvs at various concentrations as indicated in figure 3 . The in vitro transcription reaction was then initiated by addition of a mix containing $1 \mathrm{mM}$ ATP, $1 \mathrm{mM}$ CTP, $1 \mathrm{mM}$ GTP, $0.2 \mathrm{mM}$ UTP, $20 \mu \mathrm{Ci}{ }^{32} \mathrm{P}-\mathrm{UTP}$ (3000Ci/mmol) and 80 units of RNasin (Promega). After $60 \mathrm{~min}$ at $30^{\circ} \mathrm{C}$, transcripts were precipitated in $25 \%$ trichloroacetic acid. As shown in figure 3, Nuc 3 and Nuc 25 displayed a dose-dependent inhibitory effect on VSV transcription activity with 20\%, 55\% and $>95 \%$ inhibition when added at a concentration of 5 $\mu \mathrm{g} / \mathrm{ml}, 10 \mu \mathrm{g} / \mathrm{ml}$ and $100 \mu \mathrm{g} / \mathrm{ml}$, respectively. Only minor inhibitory effects, not exceeding $20 \%$ at the highest concentration, could be detected with the control antibody Nuc 1 . Thus, Nuc 3 and Nuc 25 recombinant antibodies represent good candidates to inhibit VSV RNA synthesis in vivo.

In this study we report the use of the scFv phage display technology to identify new proteins with potential antiviral activities against negative strand RNA viruses. We reasoned that the selection of molecules targeting the nucleocapsid and thus preventing RNA synthesis could represent a common strategy to block spread of these viruses. Ideally, the selected 
recombinant antibodies would interact with high affinity and specificity with the nucleocapsid and would prevent the motion of the viral RNA polymerase on this complex.

For this purpose, the phage display technology bears a certain number of advantages. The most interesting one is the possibility to perform the affinity selection with biologically functional antigens, which allows the selection for scFv recognizing conformational epitopes. Recombinant antibodies that target proteins in native state are more likely to act as neutralizing molecules in vivo as those recognizing denatured proteins. In our experiments the in vitro affinity selection was done with transcription-competent nucleocapsids and the two conformational antibodies that derived from this selection were found to efficiently block VSV transcription.

The challenge for the future will be to express these recombinant antibodies intracellularly and show that they can efficiently block VSV RNA synthesis. To be used as potential therapeutic agents, scFvs must be stably expressed inside the cell. Unfortunately, the strong reducing environment of the cytoplasm tends to prevent the formation of disulphide bonds that are necessary for the proper folding of scFv (Schouten et al., 2002). To circumvent this problem and in order to build successful intrabodies, several strategies can be proposed. One of them is to perform strategic point mutations in the $V_{H}$ and $V_{L}$ domains of the selected antibody (Ohage \& Steipe, 1999, Wirtz \& Steipe, 1999). The fusion of a module (such as the $\mathrm{C}$ region of $\kappa$ light chain $(\mathrm{C} \kappa)$ or the constant region fragment $(\mathrm{Fc})$ of $\mathrm{IgG}$ ) has also been used with success to stabilize scFv (Strube \& Chen, 2004). We are currently trying to manipulate the scFvs presented in this study in order to obtain stable intrabodies able to inhibit VSV RNA synthesis in vivo.

The recombinant antibodies describe here can easily be produced in large amounts and in soluble form in bacteria. Therefore, they will be used for immunoprecipitation analysis of viral complexes and to investigate the interaction between the nucleocapsids and their potential cellular partners.

On the other hand, Nuc 3 and Nuc 25 antibodies will also be used for structural analysis. Mapping of their binding site and resolution of the tri-dimensional structure of VSV $\mathrm{N}$ protein in complex with the antibodies may provide us with some clue for the design by structural modelling of smaller inhibitors which would be better suited for intracellular delivery. 
Figure 1: Selection of ScFv that specifically interact with VSV nucleocapsid.

A) SDS-PAGE analysis of VSV nucleocapsids. Lane 1, $1 \mu \mathrm{g}$ of gradient-purified nucleocapsid. Lane 2, 0,5 $\mu$ g of biotinylated nucleocapsid. Lanes 3 and 4, nucleocapsids captured on strepatvidin coated beads. One half of the recovered beads are loaded in each lane. Proteins were stained with Coomassie blue. $\mathrm{N}$ : nucleoprotein, *: monomers of streptavidin (13 kDa) released from the beads during SDS-PAGE. B) Ratio, for each cycle of selection, between the number of nucleocapsid-bound phages (output) and the number of scFv displaying phages used for the selection (input). C) Protein sequence alignment of the 3 scFvs used in this study. $V_{H}$ and $V_{L}$ immunoglobulin variable regions lie between AA 1-116 and 134-241, respectively. Asterisks indicate amino-acid differences between the sequences. The glycine/serine linker, the (His) ${ }_{6}$-tag and the myc epitope are also indicated.

\section{Figure 2: Functional characterization of the selected scFv.}

A) VSV-infected and non infected cytoplasmic extracts were blotted onto a nitrocellulose membrane. Recombinant antibodies from 50\% glycerol stocks were used at 1/200 dilution and mixed with an anti-myc monoclonal antibody (9E10). ScFv binding was revealed by peroxidase activity detection with a light-based ECL system (PIERCE). B) VSV nucleocapsids were immunoprecipitated from cytoplasmic extract obtained from VSVinfected cells with Nuc 1, Nuc 3 and Nuc 25. The samples were loaded on a 12 \% SDSPAGE, transferred and immunobloted with an anti-VSV polyclonal antibody used at a 1/2000 dilution. Lane Ctl: gradient-purified nucleocapsid. C) The immunoprecipitated samples described in Fig 2B were loaded on a 12 \% SDS-PAGE and stained with Coomassie blue. D) Vero cells were infected with VSV (at m.o.i. 1) for 8 hours at $37^{\circ} \mathrm{C}$. Cells were incubated with Nuc 1, Nuc 3 or Nuc 25 (at 1/100 dilution), mixed with anti-myc (9E10) and anti-His (clone HIS-1, Sigma) mAbs. Nucleocapsids were stained with a FITC-labelled anti-mouse Ig conjugate (green) whereas nuclei were stained with Hoechst (blue). Pictures were taken with a Zeiss Axioplan 2 fluorescence microscope and processed with AnalySiS 3.0 software.

Figure 3: Inhibition of VSV RNA synthesis in vitro by recombinant ScFv.

RNA synthesis was performed from detergent-disrupted VSV in presence of indicated amounts of each scFv. Incorporation of ${ }^{32} \mathrm{P}-\mathrm{UTP}$ into transcribed RNA was determined by liquid scintillation counting after TCA precipitation. Transcription activity was expressed as 
the percentage of a control reaction without scFv. Each reaction was performed in triplicate. Error bars represent the standard deviation of the data.

\section{Acknowledgements}

The authors would like to thank Dr D. Blondel (laboratoire de Virologie Moléculaire et Structurale, UMR 2472) for providing us with the VSV polyclonal antibody. We would like to thank Dr F. Perez (Institut Curie, UMR 144) for the help with the affinity selection and Dr L. Merendino for critical reading of the manuscript. F.I was supported by a grant from the Région Rhône-Alpes (contrat Emergence).

\section{References}

Arnheiter, H., Davis, N. L., Wertz, G., Schubert, M. \& Lazzarini, R. A. (1985). Role of the nucleocapsid protein in regulating vesicular stomatitis virus RNA synthesis. Cell 41, 259-67.

Chen, S. Y., Bagley, J. \& Marasco, W. A. (1994). Intracellular antibodies as a new class of therapeutic molecules for gene therapy. Hum Gene Ther 5, 595-601.

Clackson, T., Hoogenboom, H. R., Griffiths, A. D. \& Winter, G. (1991). Making antibody fragments using phage display libraries. Nature 352, 624-8.

Griffiths, A. D., Williams, S. C., Hartley, O., Tomlinson, I. M., Waterhouse, P., Crosby, W. L., Kontermann, R. E., Jones, P. T., Low, N. M., Allison, T. J. \& et al. (1994). Isolation of high affinity human antibodies directly from large synthetic repertoires. Embo J 13, 3245-60.

Lobato, M. N. \& Rabbitts, T. H. (2003). Intracellular antibodies and challenges facing their use as therapeutic agents. Trends Mol Med 9, 390-6.

Maciejewski, J. P., Weichold, F. F., Young, N. S., Cara, A., Zella, D., Reitz, M. S., Jr. \& Gallo, R. C. (1995). Intracellular expression of antibody fragments directed against HIV reverse transcriptase prevents HIV infection in vitro. Nat Med 1, 667-73.

Marasco, W. A. (1997). Intrabodies: turning the humoral immune system outside in for intracellular immunization. Gene Ther 4, 11-5.

Marasco, W. A., Haseltine, W. A. \& Chen, S. Y. (1993). Design, intracellular expression, and activity of a human anti-human immunodeficiency virus type 1 gp120 single-chain antibody. Proc Natl Acad Sci U S A 90, 7889-93. 
McCafferty, J., Griffiths, A. D., Winter, G. \& Chiswell, D. J. (1990). Phage antibodies: filamentous phage displaying antibody variable domains. Nature 348, 552-4.

Mhashilkar, A. M., Bagley, J., Chen, S. Y., Szilvay, A. M., Helland, D. G. \& Marasco, W. A. (1995). Inhibition of HIV-1 Tat-mediated LTR transactivation and HIV-1 infection by anti-Tat single chain intrabodies. Embo J 14, 1542-51.

Moyer, S. A., Smallwood-Kentro, S., Haddad, A. \& Prevec, L. (1991). Assembly and transcription of synthetic vesicular stomatitis virus nucleocapsids. J Virol 65, 2170-8.

Ohage, E. \& Steipe, B. (1999). Intrabody construction and expression. I. The critical role of VL domain stability. J Mol Biol 291, 1119-28.

Rondon, I. J. \& Marasco, W. A. (1997). Intracellular antibodies (intrabodies) for gene therapy of infectious diseases. Annu Rev Microbiol 51, 257-83.

Rose, J. K., Whitt, M.A. (2001). Rhabdoviridae: The viruses and their replication. In Fields Virology, 4th edn, pp. 1221-1244. Edited by D. M. Knipe, Howley, P.M. Philadelphia: Lippincott, Williams \& Wilkins.

Schouten, A., Roosien, J., Bakker, J. \& Schots, A. (2002). Formation of disulfide bridges by a single-chain Fv antibody in the reducing ectopic environment of the plant cytosol. $J$ Biol Chem 277, 19339-45.

Stocks, M. R. (2004). Intrabodies: production and promise. Drug Discov Today 9, 960-6.

Strube, R. W. \& Chen, S. Y. (2004). Enhanced intracellular stability of sFv-Fc fusion intrabodies. Methods 34, 179-83.

Whelan, S. P., Barr, J. N. \& Wertz, G. W. (2004). Transcription and replication of nonsegmented negative-strand RNA viruses. Curr Top Microbiol Immunol 283, 61119.

Wirtz, P. \& Steipe, B. (1999). Intrabody construction and expression III: engineering hyperstable V(H) domains. Protein Sci 8, 2245-50. 
A

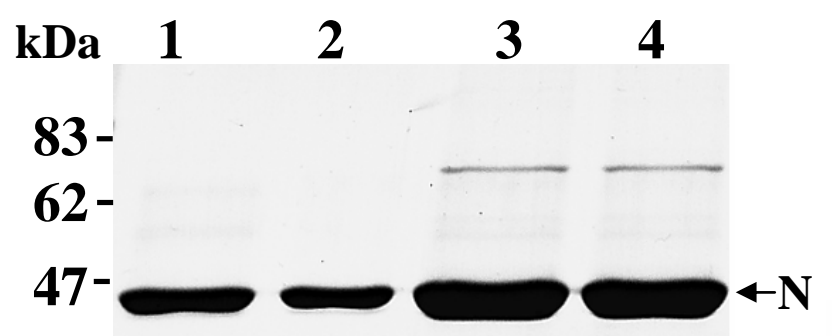

$32-$

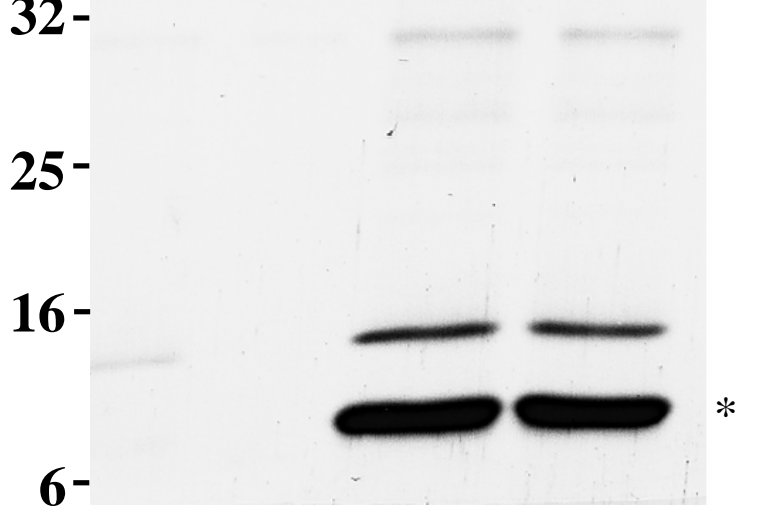

B

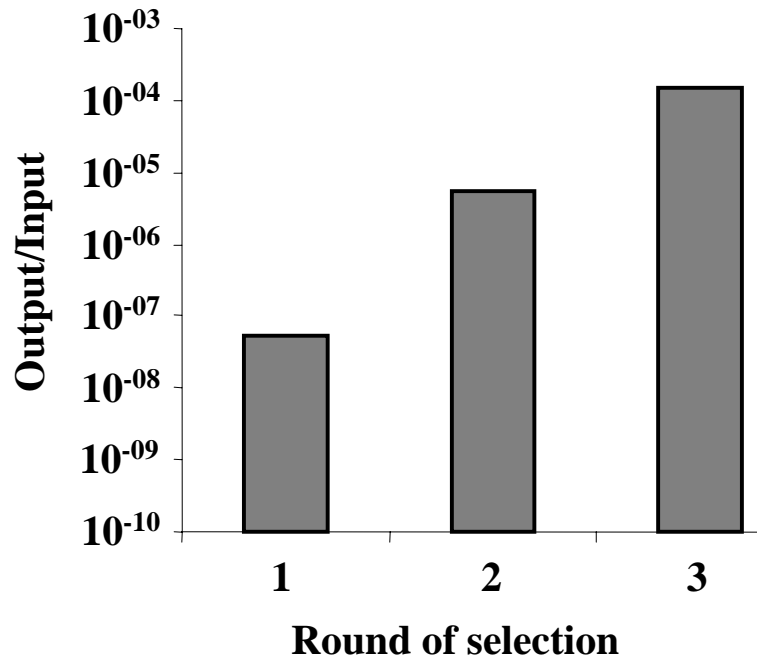

Nuc1

Nuc3

Nuc 25

110

20

30

40

50

60

70

MAEVQLLESGGGLVQPGGSIRLS CAASGFTFSSYAMSWVRQAPGKGLEWVSTI GSSGSYTDYADSVKGRE MAEVQLLESGGGLVQPGGSLRLSCAASGFTFSSYAMSWVRQAPGKGLEWVSTI GNDGGGTDYADSVKGRF MAEVQLLESGGGLVQPGGSLRLSCAASGFTFSSYAMSWVRQAPGKGLEWVSWI ASSGAATDYADSVKGRF

$$
* * * * * *
$$

80

$90 \quad 100 \quad 110 \quad 120$

130

140
Nuc1

Nuc3

Nuc 25

Nuc1

Nuc3

Nuc 25

Nuc1

Nuc3

Nuc 25
TISRDNSKNTL YLQMNSLRAEDTAVYYCAKNGYSFDYWGQ TISRD NSKHTL YLQMNS LRAEDT AVYYCAKGSGYFDYWGQGTLVTVS SGGGGS GGGGSGGGGSTDIQMT $Q$ TISRD NSKNTL YLQMNS LRAEDT AVYYCAKGTSTFDYWGQGTLVTVSSGGGGSGGGGSGGGGSTDIQMTO$$
<
$$
Linker $>$
150
160
170
180
190
200
210

SPSSLSASVGDRVTITCRASंQSI SSYLWWYQQQKPGKAPKLLIYYSASH LQSGVP SRFS GSGSGTDFTLTIS SPSSLSASVGDRVTITCRASQSI SSYLWWYQQKPGKAPKLLIYTASYLQSGVP SRFSGSGSGTDFTLTIS SPSSLSASVGD RVTITCRASQSI SSYLWWYQQKPGKAPKLLI YNASS LQSGVP SRFS GSGSGTDFTLTIS

$$
\text { * * }
$$

220

230

240

250

260

SLQPEDFATYYCQQSDT SPTTFGQGTKVE I KRAAAHHHHHH GAAEQKLISEEDLNGAA

SLQPEDFATYYCQQSYD NPATFGQGTKVEIKRAAA HHHHHH GAAEQKLISEED LNGAA

SLQPEDFAT YYCQQS YDYPST F GQGTKVEI KRAAAHHHH HHGAAEQKLISEEDLNGAA

**** 
A

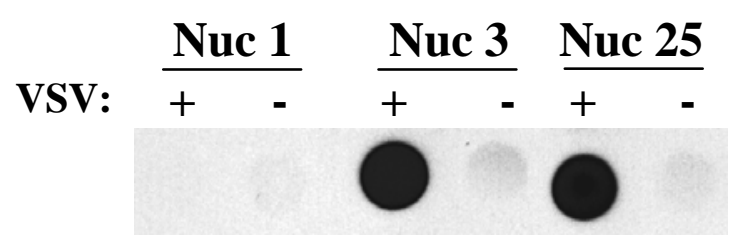

B

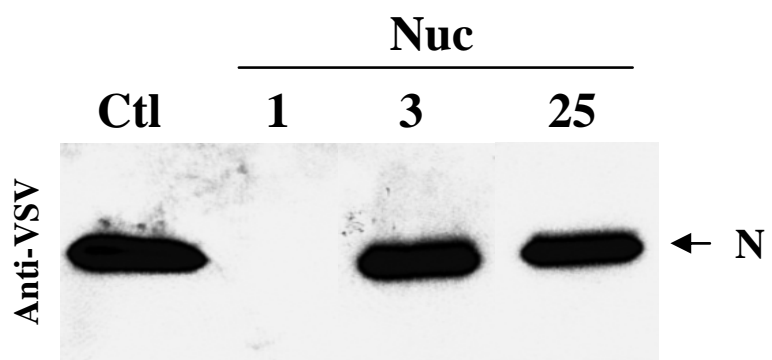

C

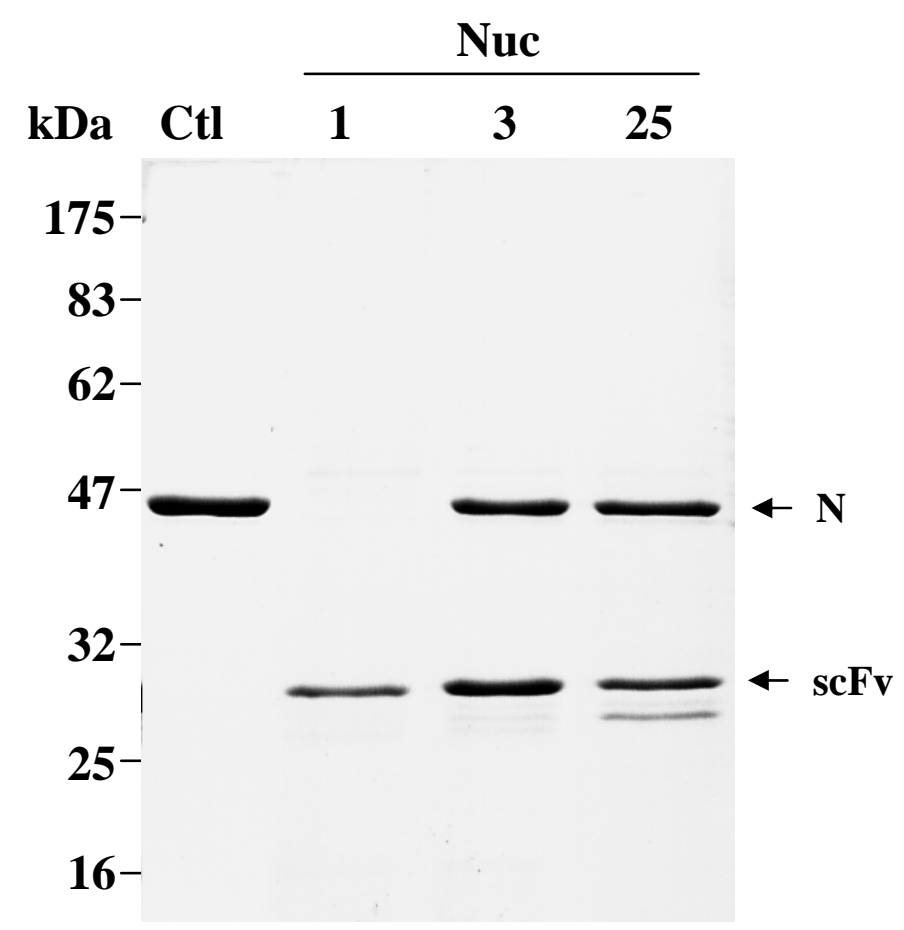

D
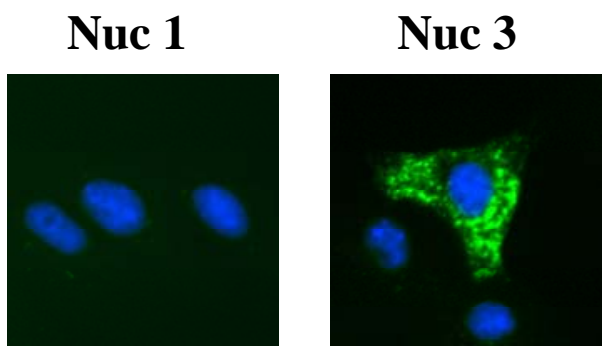

Nuc 25

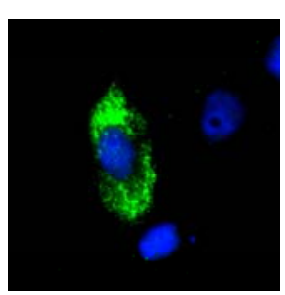




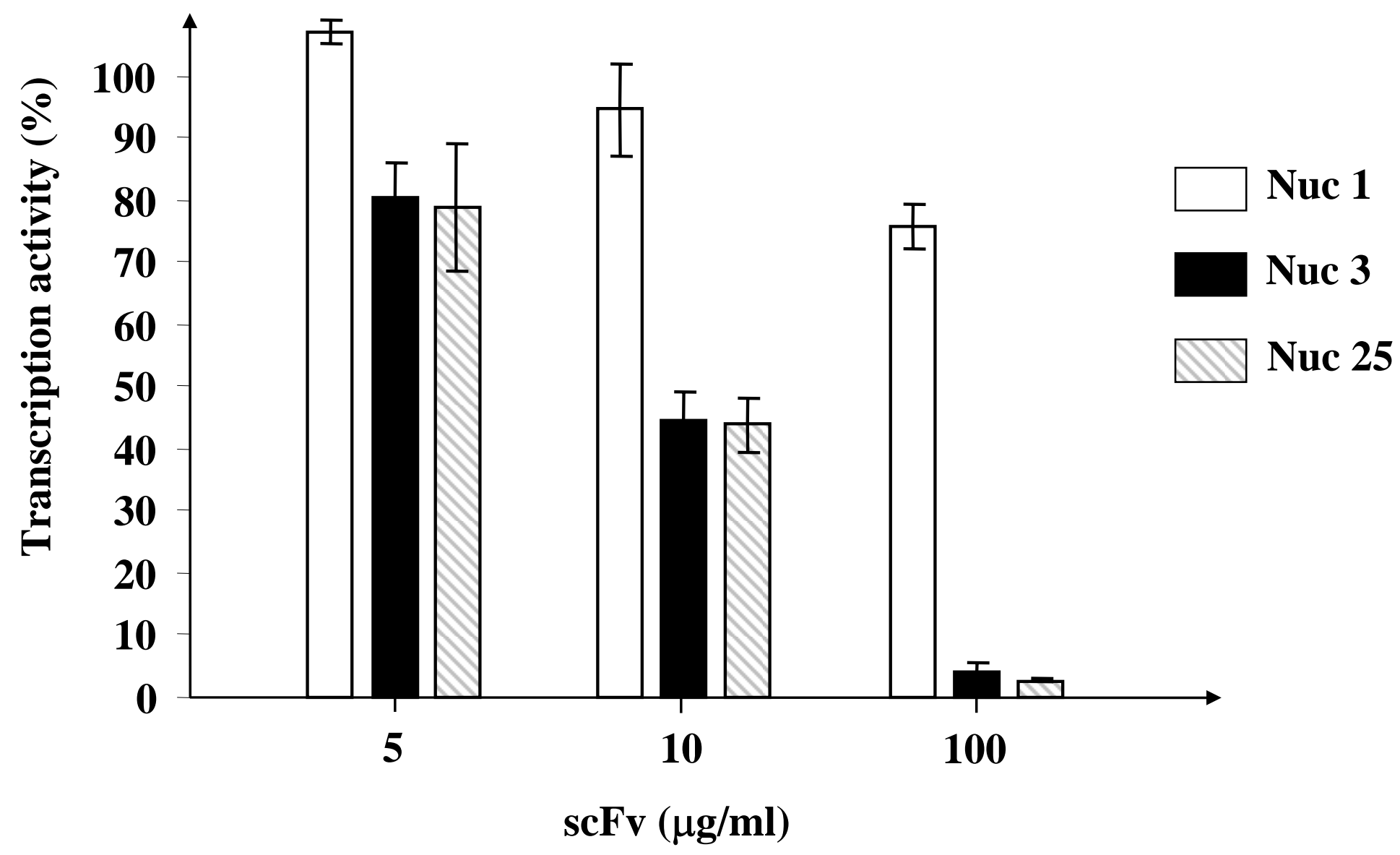

Cortay et al. Fig 3 